\title{
Das orientações oficiais às práticas instauradas em escolas municipais do Rio de Janeiro: uma investigação sobre o ensino do componente linguístico/gramatical
}

DOI: http://dx.doi.org/10.21165/el.v50i1.2989

\section{Luiz Felipe da Silva Durval'}

\section{Resumo}

Este artigo tem como objetivos: (i) investigar o ensino do componente gramatical, considerando a variação linguística e a relação gramática-texto no material proposto para o ensino fundamental da rede pública municipal do Rio de Janeiro; e (ii) contrastar os dados levantados nesse material com os Parâmetros Curriculares Nacionais (PCN) e com as diretrizes municipais para o ensino (RIO DE JANEIRO, 2013, 2016). Toda a investigação se desenvolveu em observação à proposta de ensino de gramática em três eixos, conforme Vieira $(2014,2017,2018)$. O objetivo geral do trabalho é informar sobre as práticas pedagógicas vigentes, práticas essas pensadas a partir dos PCN. Isso se justifica, pois, para se propor estratégias didáticas produtivas para o trabalho com o componente linguístico, é preciso ter conhecimento das orientações curriculares e da abordagem que se tem praticado. Os resultados aqui apresentados integram parcialmente nosso trabalho monográfico.

Palavras-chave: ensino de gramática; variação linguística; três eixos.

1 Universidade Federal do Rio de Janeiro (UFRJ), Rio de Janeiro, Rio de Janeiro, Brasil; luizfelipedurval@hotmail.com; http://orcid.org/0000-0003-4949-119x 


\title{
From official guidelines to practices in municipal schools in Rio de Janeiro: an investigation into the teaching of the linguistic/ grammatical component
}

\begin{abstract}
This article aims to: (i) investigate the teaching of the grammatical component, considering the linguistic variation and the grammar-text relationship in the material proposed for Middle School in the municipal public school of Rio de Janeiro; and (ii) contrast the information collected in this material with the Parâmetros Curriculares Nacionais (PCN) and with the municipal guidelines for teaching (RIO DE JANEIRO, 2013, 2016). All the research is based on the proposal of a "grammar teaching in three axes" (VIEIRA, 2014, $2017,2018)$. The general objective is to inform about the pedagogical practices in force, practices that were thought from the PCN. This is justified, therefore, it is necessary to know of the curricular guidelines and the approach that has been practiced to propose productive teaching strategies for working with the linguistic component. The results presented here are part of our undergraduate thesis.
\end{abstract}

Keywords: grammar teaching; linguistic variation; grammar in three axes.

\section{Introdução}

O Brasil passou por significativas transformações sociais nas três últimas décadas do século XX. Com um país cada vez mais urbano e industrial e com a universalização da educação básica garantida em Constituição, surgiram novas demandas e necessidades no campo educacional, que passava a atender, a partir de então, um público cada vez mais plural. Os Parâmetros Curriculares Nacionais - PCN (BRASIL, 1998), publicados pelo Ministério da Educação (MEC), representaram um grande esforço na tentativa de se repensar a escola e sua função social e de se formar - respeitando as diversidades regionais - uma base de conhecimento que pudesse ser partilhada em nível nacional.

Nesse momento, as discussões acerca da necessidade de melhoria do ensino de Língua Portuguesa também estavam em voga. Motivada pela difusão da Linguística no Brasil, principalmente a partir de 1970, a crítica era direcionada à Gramática Tradicional (GT). Em outras palavras, o que se criticava era o foco dado ao ensino prescritivo de gramática e a concepção de língua como apenas um conjunto de regras a serem meramente decoradas. A proposta de ensino de Língua Portuguesa vigente nas escolas consistia em apresentar aos alunos os conceitos e a metalinguagem presentes nos compêndios tradicionais de gramática para serem decorados e cobrados em provas e atividades mecânicas de classificação. Desse modo, o cenário de debates sobre o ensino de língua materna no Brasil se dividiu, colocando em lados opostos a Gramática e a Linguística. Foi em meio a esse ambiente polarizado que surgiram os PCNs de Língua Portuguesa. Como 
uma síntese dos avanços feitos a partir das críticas direcionadas ao ensino de língua, essas orientações vieram com o objetivo de estabelecer referências para as discussões curriculares da área e tentar esclarecer o objeto de estudo dessa disciplina.

Mais de vinte anos depois, questionamentos como "o quê" e "como ensinar" estão presentes na vida do professor de Português, sobretudo quando se trata da abordagem de temas gramaticais. Refletindo sobre essa questão, este artigo, que nasceu no âmbito do projeto Gramática, variação e ensino: diagnoses e propostas pedagógicas, tem como objetivo geral conhecer as práticas ${ }^{2}$ instauradas em escolas municipais do Rio de Janeiro, práticas essas pensadas a partir dos documentos oficiais, como os PCN. O intuito é observar o material didático do município na tentativa de compreender e diagnosticar as práticas pedagógicas atuais e seus efeitos. Buscaremos entender onde o ensino de língua materna tem acertado e tem sido produtivo e onde tem falhado e as causas possíveis de sua improdutividade, a fim de construir propostas pedagógicas ${ }^{3}$ que abarquem o componente linguístico de maneira mais efetiva.

\section{Pressupostos teórico-metodológicos}

Após inúmeras produções científicas de especialistas da área e de diversos debates sobre o assunto nos últimos anos, a questão do ensinar ou não gramática já está superada (ou ao menos deveria estar). Atualmente, discussões acerca do objeto de ensino (o que ensinar?), da metodologia mais adequada (como ensinar?) e dos objetivos a serem alcançados (para que ensinar?) são muito mais relevantes e produtivas.

O quadro teórico que será delineado reúne: (i) uma concepção clara de gramática, norma(s) e variação, ponto de partida que julgamos indispensável para se pensar sobre ensino de língua; e (ii) a proposta dos três eixos para o ensino de gramática, no qual se baseou a diagnose do material didático.

\footnotetext{
2 É importante salientar que, apesar de a diagnose cujos resultados serão apresentados neste artigo se basear na análise de documentos oficiais e do material didático-pedagógico, o modelo de ensino e avaliação instituído no município do Rio de Janeiro garante pouca flexibilidade ao professor em sala de aula. Portanto, uma análise das orientações e do material didático reflete, sim, as práticas instauradas no chão da escola. Além disso, para o início dessa pesquisa, permanecemos um ano letivo dentro de uma escola municipal acompanhando a rotina de diversos professores de Português.
}

3 Embora não caiba nos limites deste artigo, a construção de propostas pedagógicas já se iniciou, dentre as quais, uma para o tema da expressão de futuro, elaborada e experimentada por mim em turma de $7^{\circ}$ ano (cf. DURVAL, 2018). 


\section{Mas o que é mesmo "gramática"? 4}

Inicialmente, entender o que vem a ser gramática pode parecer algo um tanto complexo, uma vez que esta expressão pode apresentar diferentes acepções. Entretanto, os sentidos assumidos são basicamente de duas naturezas. Discorreremos brevemente sobre cada uma delas a seguir.

O termo "gramática" comumente remete a manuais modelares que descrevem o "bom uso" da língua com uma grande quantidade de regras e exceções. Essa concepção normativa tem uma razão histórica. A necessidade de elaboração de uma gramática surgiu na sociedade grega em um período de instabilidade cultural - conhecido como helenístico -, em um "momento de desmoronamento dos padrões da língua considerada a "pura", o que já mostra o ensejo da obra" (NEVES, 2012, p. 24). Portanto, a primeira gramática de que se tem notícia nasceu do interesse de gregos eruditos e teve como base textos clássicos, por exemplo, a obra de Homero, para se construir padrões de escrita com o intuito de preservação da língua local.

De igual modo, as Gramáticas Tradicionais (GTs) brasileiras foram elaboradas por especialistas tendo por base a produção de escritores consagrados da Língua Portuguesa. Durante toda a história educacional, o entendimento restrito de gramática como conjunto de padrões ideais de uso assumiu lugar privilegiado no ensino de língua materna, dando continuidade ao modelo iniciado pelos gregos. No âmbito escolar, os recortes didáticos feitos das GTs assumiram um caráter muito mais normativo do que o das próprias gramáticas, que não são constituídas apenas de prescrições, mas também de descrições. Em razão disso, o ensino de gramática se traduziu em uma abordagem metalinguística da língua com o objetivo de levar o aluno a dominar normas homogeneizantes para falar e escrever bem, enfatizando o "certo" e o "errado".

Sob outra perspectiva, existe a concepção de gramática trazida pelos linguistas e é essa que adotaremos nesta pesquisa. Durante todo o trabalho, ao utilizarmos esse termo, estaremos fazendo referência às regras naturais de funcionamento da língua. De acordo com Neves (2012, p. 29), gramática pode ser entendida como "mecanismo geral que organiza a língua". Nas palavras de Franchi (2006, p. 25), "gramática corresponde ao saber linguístico que o falante de uma língua desenvolve dentro de certos limites impostos pela sua própria dotação genética humana, em condições apropriadas de natureza social e antropológica". Portanto, gramática é o conjunto de normas que regulam a língua. Mas o que entendemos por "normas"?

40 título dessa seção faz referência ao livro homônimo, organizado por Sírio Possenti, que reúne textos de Carlos Franchi destinado a professores, publicado em 2006. 


\section{Normas e Variação}

Uma característica inegável da linguagem e que está nas bases da Sociolinguística Laboviana é a sua variabilidade. O princípio da heterogeneidade postula que a variação é inerente ao próprio sistema linguístico. Em outras palavras, toda língua natural apresenta formas alternativas - chamadas de variantes linguísticas - para um mesmo fenômeno, desde o nível fonético/fonológico até o léxico-semântico. A natureza variável da língua expressa a riqueza sociocultural produzida por cada indivíduo em sociedade. Essa variação ocorre de forma ordenada, motivada por fatores estruturais (linguísticos) e sociais (extralinguísticos). Portanto, não existe um uso que seja mais correto do que outro, sendo a língua um conjunto de variedades que revelam a realidade sociolinguística das diferentes comunidades de fala 5 .

Intimamente ligada a isso, está a questão da definição de norma. Há, basicamente, dois sentidos assumidos por essa expressão no campo da linguagem. Zilles e Faraco (2015) dizem que o primeiro está relacionado ao que é normal, ao que é comum devido à frequência de uso. Nesse sentido, norma pode ser definida como conjunto dos traços linguísticos característicos de uma determinada comunidade de fala. Portanto, contempla todo o dinamismo da realidade linguística que se apresenta, sem atribuir qualquer tipo de valor aos usos. No outro sentido, norma remete ao que é normativo, ao "como se deve dizer em determinados contextos". Trata-se, então, do que é desejável, de uma realidade construída com base em preceitos padronizadores.

Ainda sobre a questão da norma, Faraco (2008) faz algumas distinções pertinentes que ajudam a elucidar a realidade sociolinguística, principalmente, para se pensar sobre qual norma (ou quais normas) devem estar presentes em sala de aula. Há uma grande confusão conceitual em torno de norma culta e norma-padrão. Muitos artigos da própria área de Linguística usam essas duas expressões como sinônimas, ou, ainda, para designar as orientações dos instrumentos normativos. Com maior rigor conceitual, o autor sistematiza essas concepções da seguinte forma:

(i) norma-padrão - diferentemente da norma culta, não corresponde a uma variedade da língua. É um conjunto abstrato/idealizado de regras gramaticais que tem como objetivo unificar a língua, torná-la homogênea; um instrumento ideológico de combate à variação linguística.

5 Entende-se por comunidade de fala aquela que compartilha normas e atitudes sociais perante uma língua ou variedade linguística (LABOV, 1972), um grupo de indivíduos que compartilha informações linguísticas similares. 
(ii) norma culta/comum/standard - compreende as variedades praticadas por falantes que tiveram amplo acesso à cultura escrita, portanto, "consiste no conjunto de fenômenos linguísticos que ocorrem habitualmente no uso dos falantes letrados em situações mais monitoradas de fala e escrita" (p. 73).

É importante ressaltar que as variedades, das mais cultas às mais populares, têm valores sociais distintos. $\mathrm{O}$ que significa dizer que algumas normas são avaliadas positivamente, tendo certo prestígio, e outras recebem avaliações negativas, estas normalmente associadas a classes sociais mais baixas e a pessoas com baixa escolarização, reforçando o estigma. Por fim, vale ressaltar que não há uma única norma dita culta, e sim normas cultas. As variedades usadas pelos falantes cultos, apesar de similares, apresentam também variabilidade.

Onde se localizaria, então, o que ficou conhecido como "norma gramatical", aquela sistematizada por filólogos e lexicógrafos de orientação tradicional/greco-latina? Segundo Faraco (2008), a norma gramatical seria uma das instâncias de padronização da língua, que constituiria uma espécie de meio termo entre as prescrições da normapadrão e as descrições da norma culta. Trata-se, então, de um conjunto de fenômenos considerados cultos pelos melhores gramáticos, baseado na flexibilização de um modelo estipulado no século XIX, abarcando usos das variedades cultas.

\section{Ensino de gramática em três eixos}

A concepção de ensino de gramática em três eixos é uma proposta elaborada por Vieira (2014, 2017, 2018) no âmbito da disciplina Gramática, variação e ensino, do Mestrado Profissional em Língua Portuguesa (PROFLETRAS). Diagnosticando que um dos maiores problemas a serem enfrentados pelo professor de Português reside no ensino de gramática, a autora apresenta uma proposta experimental para uma abordagem didáticopedagógica mais produtiva no tratamento de temas gramaticais. Essa proposta objetiva conjugar os componentes gramaticais à produção de sentido, evitando, no entanto, tomálos como apenas instrumentos para as práticas de letramento ou como um conjunto de regras homogeneizantes. Portanto, o modelo de ensino em três eixos a ser apresentado a seguir consiste na abordagem reflexiva da gramática, integrada às atividades de leitura e produção de textos, e considerando, ainda, a variação linguística.

O Eixo I propõe uma abordagem reflexiva da gramática baseada, dentre outros autores, nos postulados de Franchi (2006). Segundo o autor, as atividades escolares com o componente gramatical seriam de três naturezas: a linguística, a epilinguística e a metalinguística.

A atividade linguística consiste no exercício do "saber linguístico" da criança advindo de sua gramática internalizada por suas experiências cotidianas com a linguagem 
(FRANCHI, 2006). Trata-se, portanto, de explorar esse saber trazido pelo aprendiz através de atividades de produção e compreensão de textos de variados gêneros (orais ou escritos), criando "as condições para o desenvolvimento sintático dos alunos" (Ibidem, p. 98).

Para se chegar a esta finalidade, tem-se, então, a atividade epilinguística, que consiste na prática de levar o aluno a operar sobre a própria linguagem, comparando as expressões, transformando-as, experimentando novos modos de construção canônicos ou não (FRANCHI, 2006). Portanto, não se trata de inserir classificações ou nomenclaturas, mas atividades estimuladas pelo professor para que o aprendiz participe, contribua e reflita sobre as diferentes possibilidades de arranjos linguísticos, praticando a diversidade dos fatos gramaticais de sua língua.

Desse contato com os fatos da língua, a partir das atividades linguística e epilinguística, surge "a necessidade de sistematizar um 'saber' linguístico que se aprimorou e se tornou consciente" (Ibidem, p. 98). É nesse momento oportuno que a atividade metalinguística naturalmente acontece, como um "trabalho inteligente de sistematização gramatical" que permite descrever a linguagem a partir da observação do caráter sistemático das construções, repletas de significação. Como ponderam Pires de Oliveira e Quarezemin (2016, p. 33), "parte essencial da reflexão sobre uma língua é construir os termos para entendê-la". Através de atividades dessas naturezas, o aluno compreende que a gramática não é algo pronto e rígido com sua nomenclatura que não faz sentido algum, mas um conjunto de fenômenos que apresenta regularidades estruturais passíveis de categorização e rótulos que refletem sua análise.

Contudo, as ações do professor em sala de aula não devem se limitar apenas à reflexão sobre o caráter sistemático da língua e sobre suas possibilidades operacionais. Portanto, é necessário que o trabalho com o componente linguístico, sem deixar de se alinhar a uma abordagem reflexiva, esteja integrado ao plano interacional, tomando os fenômenos gramaticais como recursos expressivos para a construção do sentido do texto. Assim sendo, o Eixo II se fundamenta nas propostas de Neves (2006) e Pauliukonis (2011) para demonstrar a produtiva relação entre gramática e o nível textual-discursivo. Essas duas propostas, que reconhecem os elementos gramaticais - dos vocábulos formais, com sua constituição morfofonológica, passando pela construção sintagmática e oracional, até a construção e inter-relação de períodos - como matérias produtoras de sentido permite reafirmar a desejável articulação entre o ensino de gramática e as atividades de leitura e produção de textos.

No âmbito do Eixo III, entende-se que o ensino de gramática deve contemplar a heterogeneidade inerente a todas as línguas, como já demonstrou a Teoria da Variação e Mudança (WEINREICH; LABOV; HERZOG, 1968), seja para cumprir os propósitos voltados mais propriamente ao componente gramatical (expressos no Eixo I), seja para promover 
as competências de leitura e de produção textual a partir dos expedientes linguísticos (como proposto no Eixo II).

Em linhas gerais, os três eixos propostos por Vieira $(2014,2017,2018)$ devem ser trabalhados, sempre que possível, de forma conjugada, pois, em muitos casos, uma frente de trabalho viabilizará as duas outras. 0 ensino de gramática como atividade reflexiva (Eixo 1), aliado ao desenvolvimento da competência comunicativa (Eixo 2), deve sempre considerar a variação linguística como condição para a promoção do letramento, para que o aluno use ou reconheça as mais diversas construções linguísticas.

\section{Metodologia}

O primeiro procedimento metodológico adotado para a realização desta pesquisa foi a análise dos documentos oficiais. Iniciamos pelos Parâmetros Curriculares Nacionais ( $3^{\circ}$ e $4^{\circ}$ ciclos) a fim de observar as diretrizes gerais formuladas para o ensino de língua materna. Concomitantemente a isso, fizemos uma breve análise das Orientações Curriculares do município do Rio de Janeiro para identificar em que medida os PCN serviram de base para a elaboração do currículo municipal. Além disso, buscamos identificar, nessas orientações, os objetivos em relação ao ensino de língua materna e o lugar dado à variação linguística nesse processo.

Em um segundo momento, partimos para o levantamento de dados nos Cadernos de apoio pedagógico elaborados pela Secretaria Municipal de Educação do Rio de Janeiro. Esses Cadernos trazem inúmeras questões para fixação do conteúdo e se apresentam em duas versões: do professor (com gabarito) e do aluno. Todos os alunos recebem esse material a cada dois meses. A investigação se ocupou de três questões fundamentais: (i) qual é o lugar do componente gramatical nesse material?; (ii) há articulação entre gramática e atividades de leitura e produção de textos?; e (iii) a variação linguística é abordada? Com base nos resultados obtidos, investigamos como as orientações curriculares do município do Rio de Janeiro (RIO DE JANEIRO, 2013) dialogam com as diretrizes de avaliação discente (RIO DE JANEIRO, 2016) e se o conteúdo encontrado nos Cadernos Pedagógicos está em consonância com estas. Essas diretrizes de avaliação são matrizes de referência que apontam para o professor os critérios que devem ser levados em consideração na correção da produção textual dos alunos. A produção textual é aplicada como avaliação ao final de cada bimestre.

Como critério para a identificação de questões gramaticais, estabelecemos o reconhecimento de expedientes de qualquer nível linguístico-gramatical (fonéticofonológico, morfológico, morfossintático, sintático) para a construção de significados, identificados por metalinguagem ou não. Não foram consideradas como "gramaticais" questões de natureza lexical ou de compreensão/interpretação exclusivamente do plano das ideias ou das relações entre ideias em geral. Para o reconhecimento das questões 
específicas de compreensão textual, o trabalho foi inspirado em Marcuschi (2008). Nesse rótulo, estão reunidas questões baseadas em: perguntas de reconhecimento da macroestrutura textual, informação por pronta recuperação, inferências e deduções, significação de itens lexicais/expressões e relação entre ideias/enunciados.

\title{
Os Parâmetros Curriculares Nacionais de Língua Portuguesa $\left(3^{\circ} \mathrm{e}\right.$ $4^{\circ}$ ciclos do Ensino Fundamental)
}

Os Parâmetros Curriculares Nacionais de Língua Portuguesa (PCN-LP) se dividem em duas partes: (i) apresentação da área de Língua Portuguesa, que aponta os principais problemas do ensino tradicional e traz discussões sobre a natureza da linguagem, o texto como unidade básica de ensino e as implicações da questão da variação linguística para a prática pedagógica; e (ii) Língua Portuguesa no terceiro e no quarto ciclos, que estabelece os objetivos de ensino e aborda os conteúdos específicos a serem trabalhados nesse segmento, além do tratamento didático dispensado a esses conteúdos.

Na primeira parte, o documento rompe com a suposta prática escolar de até então, concentrada na língua em si mesma, e destaca para o ensino-aprendizagem de língua materna uma importância muito mais sócio-política, ressaltando a função da escola no que tange à educação linguística:

\begin{abstract}
O domínio da linguagem, como atividade discursiva e cognitiva, e o domínio da língua, como sistema simbólico utilizado por uma comunidade linguística, são condições de possibilidade de plena participação social. Pela linguagem os homens e as mulheres se comunicam, têm acesso à informação, expressam e defendem pontos de vista, partilham ou constroem visões de mundo, produzem cultura. Assim, um projeto educativo comprometido com a democratização social e cultural atribui à escola a função e a responsabilidade de contribuir para garantir a todos os alunos o acesso aos saberes linguísticos necessários para o exercício da cidadania. (BRASIL, 1998, p. 19).
\end{abstract}

Portanto, os objetivos que se desejam atingir com o ensino de língua portuguesa nas escolas não se resumem mais em apenas ensinar a "ler e escrever". Para que se tenha domínio da língua, é necessário também levar o aprendiz a refletir sobre fenômenos diversos da língua, considerando a variação linguística, combatendo preconceitos e garantindo participação social. Temos então uma concepção de língua como atividade discursiva, que prioriza o desenvolvimento da competência comunicativa do aluno, considerando os diferentes contextos discursivos orais e escritos.

Já na segunda parte, onde se encontram os direcionamentos para o trabalho com a língua em sala de aula, são estabelecidas as chamadas práticas de linguagem. Essas práticas são construídas sobre três pilares: escuta de textos orais e leitura de textos 
escritos; produção de textos orais e escritos; e análise linguística. O texto é, portanto, o objeto privilegiado em todas essas práticas.

As orientações trazidas nos PCN estabelecem como papel da escola no que tange ao ensino de língua materna levar o aluno a expressar-se adequadamente tanto na fala quanto na escrita, e refletir sobre o funcionamento da língua, principalmente, no plano da interação, tornando esse o ponto de chegada das aulas de Português. Pires de Oliveira e Quarezemin (2016) salientam que o eixo foi deslocado do decorar regras da gramática normativa para a produção e leitura de textos, sem a preocupação de revisitar o conceito de gramática para ressignificá-lo. "A gramática foi oficialmente expulsa da sala de aula e continuou de modo tradicional e mais forte, porque agora apresentada como um instrumento sem importância" (Ibidem, p. 29). Segundo as autoras, faz falta uma visão científica sobre a gramática, vista nos documentos, ainda de maneira muito tradicional, apenas como recurso para o ensino da escrita.

Um ponto muito positivo a ser destacado nos PCN é a ênfase dada ao conhecimento sociolinguístico do aluno. As questões de variação linguística estão bastante presentes no documento. Nota-se a preocupação de levar o aluno a reconhecer e a refletir sobre a diversidade linguística do português falado no Brasil para que esteja preparado em relação ao uso da língua nos mais diferentes contextos e para que aceite, com respeito e como fonte de expressão cultural, a variabilidade da língua. Sobre essa questão, salientam os Parâmetros Curriculares Nacionais (BRASIL, 1998, p. 31):

No ensino-aprendizagem de diferentes padrões de fala e escrita, o que se almeja não é levar os alunos a falar certo, mas permitir-lhes a escolha da forma de fala a utilizar, considerando as características e condições do contexto de produção, ou seja, é saber adequar os recursos expressivos, a variedade de língua e o estilo às diferentes situações comunicativas: saber coordenar satisfatoriamente o que fala ou escreve e como fazê-lo; saber que modo de expressão é pertinente em função de sua intenção enunciativa - dado o contexto e os interlocutores a quem o texto se dirige. A questão não é de erro, mas de adequação às circunstâncias de uso, de utilização adequada da linguagem.

\section{Orientações oficiais do município e os Cadernos Pedagógicos}

Em 2009, todo o currículo das escolas municipais da cidade do Rio de Janeiro foi repensado, seguindo as diretrizes estabelecidas pelos Parâmetros Curriculares Nacionais. Nesse novo modelo, o ano letivo ficou organizado em quatro bimestres, com orientações específicas para cada um desses bimestres. Além da reformulação da matriz curricular, que estabeleceu os descritores bimestrais (espécie de guia para as práticas pedagógicas), a equipe da Secretaria Municipal de Educação (SME) elaborou um material de apoio didático para cada disciplina, os chamados Cadernos Pedagógicos. 
$\mathrm{Na}$ área de Língua Portuguesa, esses Cadernos são organizados por gêneros textuais, em torno dos quais toda a reflexão linguística deve ser estruturada a fim de desenvolver a competência linguístico-discursiva do aluno. Portanto, nesse novo modelo pedagógico, a prática de análise linguística ocorre quando se reflete sobre a organização do texto. Vale ressaltar que cada bimestre foca em um determinado gênero textual e, ao final desse período, o aluno deve fazer uma avaliação oficial elaborada pela SME, que consiste em produzir um texto que se enquadre no gênero estudado naquele bimestre. Sobre essa questão, esclarece Lima (2017, p. 119):

Com base nos "Descritores Bimestrais", que se repetem bimestralmente, são elaborados cadernos pedagógicos para o trabalho em sala de aula [...]. Nesses cadernos, os descritores são explorados através de textos e atividades. Embora sejam apresentados como apoio para a prática de ensino, seu uso é indispensável, uma vez que seu conteúdo é relevante para as provas no final do bimestre, pois indicarão como se encontra o ensino nas escolas. Dessa forma, o professor deve necessariamente utilizar os cadernos para desenvolver nos alunos as habilidades que serão testadas, não somente nas provas internas como também em avaliações externas, como a Prova Brasil, por se tratar dos mesmos descritores. Essa abordagem parece garantir que esses descritores sejam tratados exaustivamente, o que - consequentemente - implica melhorias para a rede de ensino.

Observando as orientações curriculares do município (RIO DE JANEIRO, 2013), depreendem-se pressupostos quanto ao trabalho com a linguagem em consonância com o que sugerem os PCNs. Os trechos a seguir destacados sintetizam as orientações:

[...] a prática de análise linguística constitui-se um trabalho de reflexão sobre a organização do texto, resultado de opções temáticas e estruturais feitas pelo autor. Sob essa ótica, o texto deixa de ser o ponto de partida para se estudar "gramática", e sua construção passa a ser objeto do ensino. (RIO DE JANEIRO, 2013, p. 8).

Como se pode verificar, é a construção da unidade textual, a partir de sua materialização em diversos gêneros, o objeto de estudo privilegiado. O componente gramatical é concebido como matéria que provê efeitos de sentido para o plano da construção textual.

No que se refere à variação linguística, esse documento deixa claro que as aulas não devem ser pautadas no ensino prescritivo de gramática, propondo uma abordagem descritiva das diversas variantes linguísticas, com respeito a todas, mas sem deixar de promover o que se identifica como "variante linguística padrão".

[...] as variantes linguísticas não são classificadas como certas ou erradas, melhores ou piores, pois constituem sistemas linguísticos eficazes dadas as 
especificidades das práticas sociais e hábitos culturais das comunidades. Sendo assim, é papel fundamental da escola garantir a todos os seus alunos acesso à variante linguística padrão. Entretanto, é fundamental, também, o respeito à existência das diferentes variantes como prática essencial para o exercício da cidadania. (Ibidem, p. 7-8).

Observando as diretrizes de avaliação discente (RIO DE JANEIRO, 2016), verificamos que elas estabelecem quatro aspectos que devem nortear a avaliação da produção escrita do aluno. São eles: estrutura, coerência, coesão e uso da língua. Os dois primeiros aspectos estão intimamente ligados aos gêneros estudados em cada bimestre e ano escolar, tendo sido estabelecidos indicadores distintos para cada um deles. Os dois outros aspectos coesão e uso da língua - são comuns a todos os anos escolares e se referem ao uso da norma culta da língua.

Com o foco voltado para a concepção de língua como instrumento de interação social, assim como os PCN, as Orientações Curriculares propõem um ensino de gramática sobretudo como instrumento a serviço da organização textual e do discurso, o que, ao que tudo indica, acaba por limitar a exploração de recursos linguísticos em seus diversos níveis. Nas Diretrizes de avaliação da produção escrita, não há, entretanto, indicação de componentes que exijam efetivamente reflexão linguística, mas a proposta de utilização de estruturas consideradas eficientes na redação.

\section{Diagnose do material didático}

A fim de fazer uma avaliação do impacto das orientações oficiais sobre as práticas pedagógicas das aulas de Português, tomamos como amostra o já referido material, os chamados Cadernos de Apoio Pedagógico. Essa escolha se deve ao fato de esse material espelhar muito do que foi proposto nos PCN, tendo como base para a formulação das Orientações curriculares em nível municipal as concepções de língua e ensino trazidas nesse documento.

A diagnose do tratamento dos dados no material foi feita em duas etapas: primeiramente, fizemos uma análise detalhada do componente gramatical no $6^{\circ}, 7^{\circ}, 8^{\circ}$ e $9^{\circ}$ anos do material referente ao ano de 2016; depois, tecemos considerações acerca dos dados levantados segundo a concepção de ensino de gramática em três eixos (VIEIRA, 2014, 2017, 2018).

\section{O componente gramatical nos Cadernos direcionados ao Ensino Fundamental II}

Para a diagnose do material proposto nos Cadernos Pedagógicos de Língua Portuguesa destinados aos $6^{\circ}, 7^{\circ}, 8^{\circ}$ e $9^{\circ}$ anos para o ano de 2016, todo o segundo segmento do Ensino Fundamental da rede pública municipal do Rio de Janeiro, traçamos dois objetivos 
principais que orientaram nossa análise: (i) investigar o ensino do componente gramatical, considerando a variação linguística e a relação gramática e texto no material proposto; e (ii) contrastar os dados levantados nesse material com as orientações curriculares da Secretaria Municipal de Educação e com as diretrizes municipais de avaliação discente.

\section{Levantamento dos dados}

O Gráfico 1 mostra a distribuição dos dados encontrados nos Cadernos analisados pelos tipos de questões elaboradas.

Gráfico 1. Questões presentes nos Cadernos Pedagógicos dos 6, 7º, $8^{\circ}$ e $9^{\circ}$ anos -2016

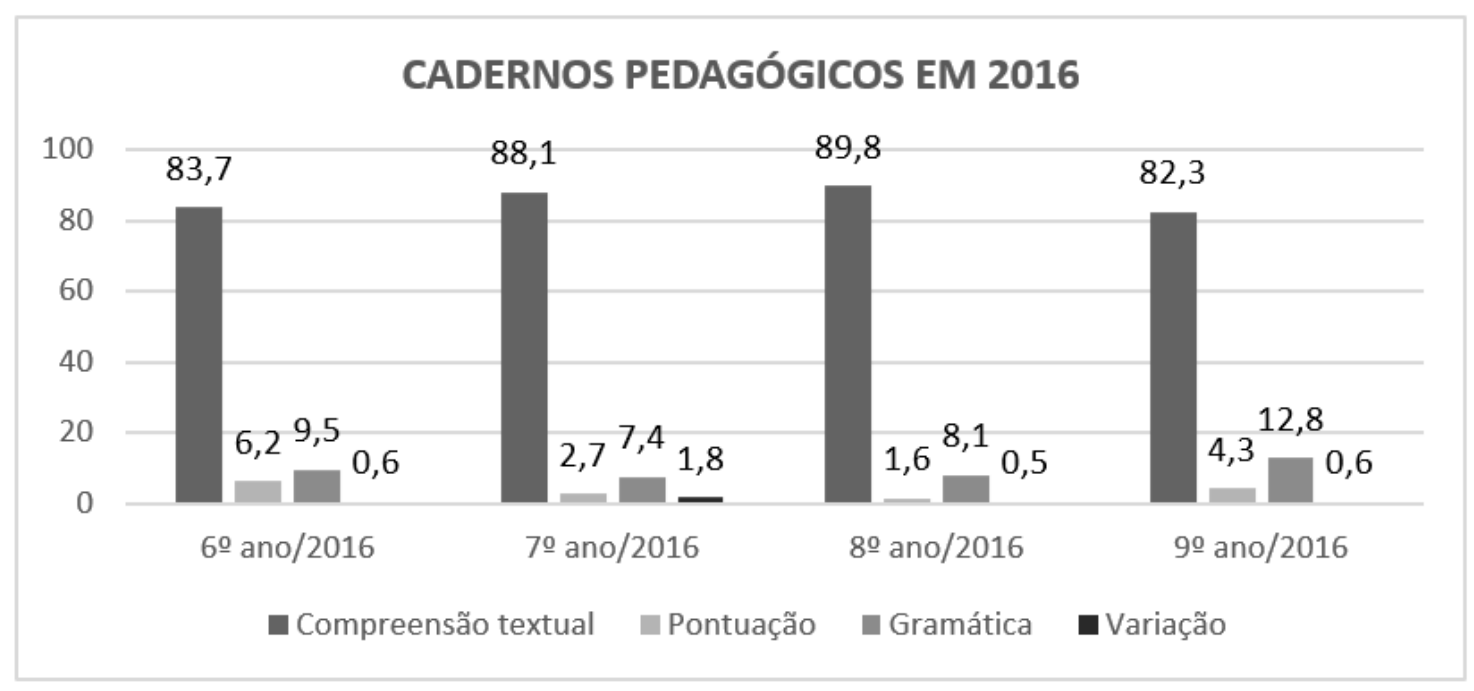

Fonte: Elaboração própria

Gráfico 2. Uso de metalinguagem nas questões de gramática nos Cadernos Pedagógicos (2016)

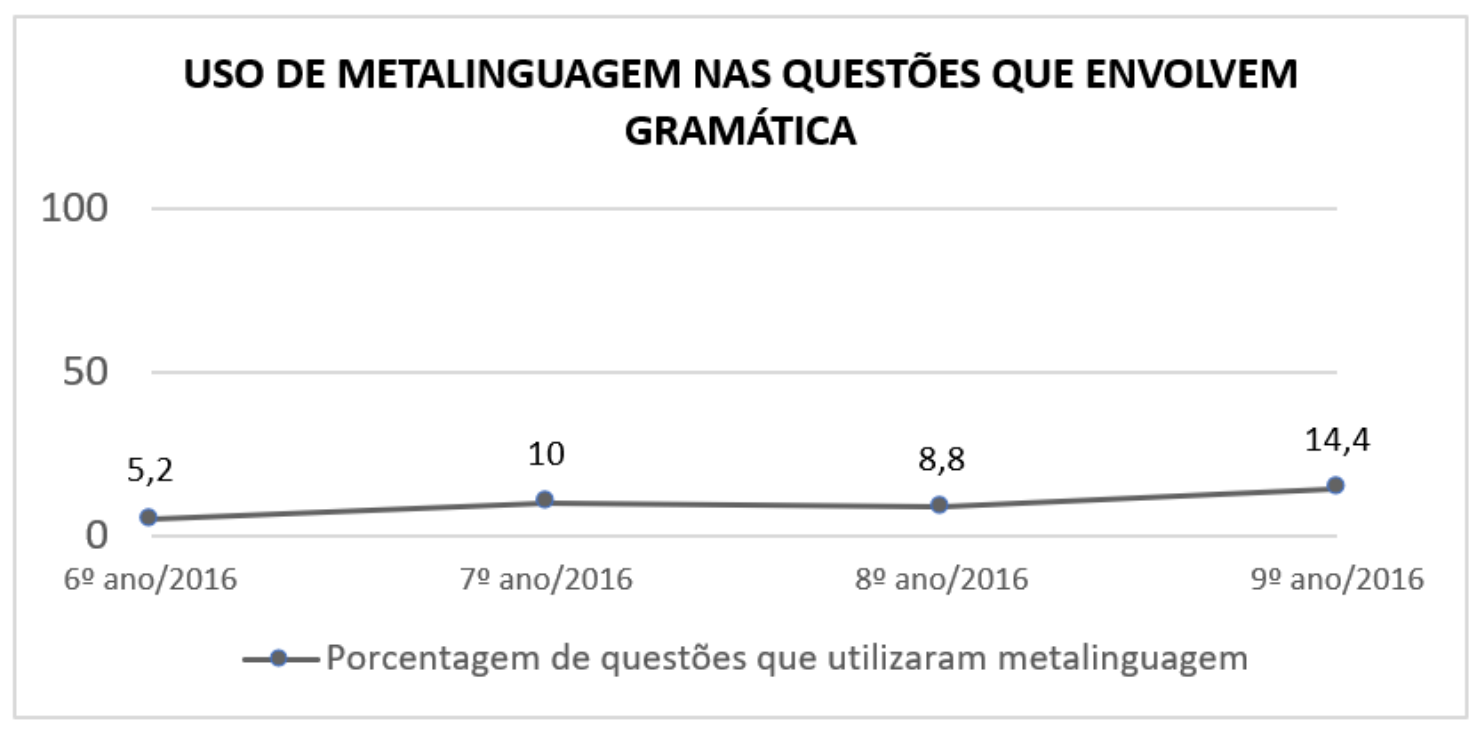

Fonte: Elaboração própria 
O primeiro gráfico mostra a distribuição por assunto das questões presentes no material destinado ao segundo segmento do ensino fundamental no ano de 2016 , do $6^{\circ}$ ao $9^{\circ}$ ano. No total, foram analisadas 2.251 questões nos dezesseis cadernos (quatro de cada ano escolar) de 2016. Questões de gramática representam em média 10\% das questões do caderno. Questões de variação linguística são praticamente inexistentes e, quando aparecem, se limitam a uma abordagem teórica do tema, sem reflexão sobre regras efetivamente variáveis. A título de comparação entre o início e o fim do ciclo, do total de 612 questões observadas nos cadernos dos quatro bimestres do $6^{\circ}$ ano, apenas 9,5\% estão relacionadas com conteúdo gramatical, o que corresponde em números absolutos a 58 questões. Já nos cadernos bimestrais do $9^{\circ}$ ano, a porcentagem de atividades dessa natureza teve um pequeno aumento, registrando um percentual de 12,8\% (104 em números absolutos), considerando o total de 814 questões analisadas. Abaixo, listamos os temas abordados nas questões que envolviam gramática em ambos os anos escolares de forma explícita ou não. Do total de 162 questões, verificamos a presença dos seguintes tópicos: conectivos coordenativos e adverbiais (41,4\%); pronome (35,8\%); advérbio (12,9\%); verbo (3,1\%); diminutivo (2,9\%); adjetivo (2,2\%) e numeral (1,7\%). Esses temas são recorrentes em todo o segmento.

Em relação ao tratamento explícito de temas gramaticais, montamos o Gráfico 2 para se ter uma noção mais ampliada da utilização da metalinguagem. Em nossa análise, não observamos qualquer progressão lógica na inserção de atividades metalinguísticas. Dentre as 58 questões de gramática analisadas nos Cadernos do $6^{\circ}$ ano, 5,2\% utilizaram metalinguagem. Das 30 questões dessa natureza encontradas nos Cadernos direcionados ao $7^{\circ}$ ano, $10 \%$ fizeram uso desse recurso. Já no $8^{\circ}$ ano, esse número caiu para $8,8 \%$, e voltou a subir, contemplando 14,4 \% das questões que envolviam temas gramaticais nos Cadernos destinados ao $9^{\circ}$ ano. Há a tendência a evitar termos técnicos por vocábulos do léxico comum: em vez de conjunção, utiliza-se "palavra"; substantivos, pronomes ou adjetivos são designados de forma genérica e pouco informativa como "termo" ou "expressão".

Não defendemos, aqui, o uso da metalinguagem nos moldes de uma tradição escolar que baseie seu ensino em regras fixas e rígidas, que revista as atividades gramaticais com excessos de terminologia, com a artificialidade da análise pela análise, com a conteudização da metalinguagem a ponto de ser aspecto privilegiado nas provas e testes. Cabe, entretanto, uma abordagem gramatical que abarque naturalmente a metalinguagem, como instrumento para a construção do saber linguístico, recurso que deve estar integrado às atividades linguísticas e epilinguísticas a serem desenvolvidas em sala de aula.

A atividade metalinguística que efetivamente esteja conjugada às atividades de reflexão sobre o funcionamento e as possibilidades de nossa língua apresentará ao aluno termos que o remeterão a formas e organizações linguísticas específicas. Ademais, se nós, seres humanos, naturalmente, categorizamos tudo que vemos e sentimos, por que não 
nomearmos os mecanismos de funcionamento e categorizarmos os elementos que compõem o sistema linguístico? Acrescente-se, ainda, que, para além da prática que se desenvolve em termos cognitivos, a atividade metalinguística permite falar sobre a língua de maneira mais econômica. Uma boa condução da gramática como atividade reflexiva possibilitará a inserção da metalinguagem de maneira inteligente e numa dosagem adequada a cada ano e estágio escolar.

De fato, os Cadernos pedagógicos cumprem o objetivo de desenvolver atividades diversas de leitura/compreensão e produção textuais, a partir dos gêneros escolhidos. No entanto, observamos, novamente, a escassez ou ausência de temas gramaticais importantes. Ainda não há uma abordagem sistemática, mesmo que exclusivamente epilinguística, de elementos estruturais referentes aos diferentes níveis da gramática.

Quanto à sistematização do conhecimento, encontramos, nos quatro anos escolares analisados, apenas seis tentativas de sistematização, materializadas em quadros com sínteses de conteúdo. Os assuntos trazidos nessas sínteses se resumiam a discurso direto/indireto, uso de recursos da linguagem para efeito de sentido e sobre coesão.

No que se refere à variação linguística, é importante destacar que, embora as diretrizes de avaliação discente priorizem temas relativos à norma-padrão, os Cadernos Pedagógicos não preparam o aluno para esse critério avaliativo. Além de o número de questões sobre variação linguística ser irrisório (menos de 1\% em média), é importante observar que temas como pontuação e concordância verbal e nominal, critérios de correção segundo as Diretrizes de Avaliação, não foram sequer trabalhados nos Cadernos ao longo dos anos observados.

No tratamento da pontuação, é curioso que, não obstante a enorme dificuldade dos alunos em colocar pontos segmentando períodos, o trabalho com a pontuação se dá quase exclusivamente pelo viés estilístico, sem considerar a estrutura da frase. E, por mais que a proposta se desenvolva por esse viés, o material não busca salientar que as variadas possibilidades de pontuar e os efeitos de sentido pretendidos estão intimamente relacionados aos gêneros textuais/aos contextos discursivos nos quais os sinais se manifestam. Os sinais abordados ficaram restritos àqueles utilizados em contexto dialogal (travessão, dois pontos, aspas, ponto de exclamação).

\section{Uma análise em três eixos: gramática, texto e variação}

Buscando relacionar a análise feita dos Cadernos Pedagógicos aos três eixos para o ensino de gramática propostos por Vieira $(2014,2017,2018)$, podemos fazer as observações a seguir. 


\section{Eixo I - reflexão linguística}

Conteúdos gramaticais, entendidos como elementos formais relativos aos diferentes níveis da gramática, são raros e com baixo estímulo à reflexão linguística. A prioridade está na identificação de referentes, identificação de valores semânticos e substituição de palavras.

Como se pôde observar, o tratamento dos temas linguísticos fica restrito a alguns temas (como pronomes, conectivos e advérbios), de modo que o trabalho gramatical assume um perfil instrumental e limitado aos textos em questão. Desse modo, a prática de análise linguística é insuficiente para cumprir as diretrizes formuladas para o ensino de língua materna em geral, que poderia ser indutivamente construído (atividades linguísticas e epilinguísticas) e sistematizado (metalinguísticas), conforme Franchi (2006), considerando a diversidade de tópicos que configuram a Língua Portuguesa. Apesar do aumento de $5,2 \%$ no $6^{\circ}$ ano para $14,4 \%$ no $9^{\circ}$ ano, o uso de metalinguagem contempla em média $9 \%$ das questões de gramática, o que não permite uma sistematização inteligente do conhecimento linguístico abordado. Raras são as tentativas de sistematizações em todo o material analisado.

\section{Eixo II - gramática e produção de sentidos}

A maior parte das questões que abordam temas gramaticais trabalha o eixo da gramática e produção de sentidos, eixo de inegável importância ao ensino. No entanto, esse trabalho é limitado e se dá apenas no nível macroestrutural do texto, restringindo-se a basicamente dois grupos temáticos: coesão e retomada referencial.

A gramática está a serviço da semântica do texto, mas há pouca ou nenhuma exploração de recursos linguísticos do nível da frase (predicação, organização sintática e papéis semânticos, efeitos da sintaxe para a pontuação, dentre outros) que também colaboram para a coesão textual, o que impossibilita o desenvolvimento de habilidades gerais previstas até mesmo nas Orientações oficiais do próprio Município.

\section{Eixo III - variação linguística}

O tratamento da variação é escasso, não possibilitando a prática de discussões reflexivas sobre temas efetivamente variáveis, conforme os três contínuos propostos em BortoniRicardo $(2005)^{6}$ e a pluralidade de normas, conforme Faraco (2008). Não se desenvolveu minimamente um método para a chamada "pedagogia da variação linguística" (Cf. ZILLES; FARACO, 2015). Observam-se, ainda, poucas questões sobre variação, que acabam por trabalhar o tema no plano teórico, com graves equívocos conceituais.

6 Referimo-nos aos contínuos de oralidade-letramento, de monitoração estilística e de urbanização, que não cabem ser detalhados neste artigo. 


\section{Considerações finais}

De fato, os Cadernos pedagógicos cumprem o objetivo de desenvolver atividades diversas de leitura/compreensão e produção textuais, a partir dos gêneros escolhidos com abundantes exercícios voltados a essa prática. No entanto, ao que parece, faz falta uma orientação curricular que evite que a reflexão linguística, por ser unicamente instrumental e particular aos textos trabalhados, seja determinada casuisticamente, tão-somente a partir do material mais saliente encontrado nos textos selecionados. Duas consequências graves dessa abordagem são (i) a falta de conhecimento reflexivo acerca de categorias básicas organizadoras da língua, até mesmo no nível da sentença, e (ii) a ausência de uniformidade no desenvolvimento do trabalho escolar com Língua Portuguesa.

Considerando os três eixos para o ensino de gramática (VIEIRA, 2014, 2017, 2018), é flagrante o desequilíbrio do material trabalhado, que basicamente desenvolve atividades de leitura como mero componente de compreensão textual sem a manipulação de recursos gramaticais. Quando essa manipulação acontece, o eixo relativo à gramática e sentidos do texto é priorizado, mas de forma limitada, com raro uso de categorias para sistematização e com temas quase exclusivos da macroestrutura textual, que se repetem ao longo de todo o material, seja do $6^{\circ}$, seja do $9^{\circ}$ ano. Assim, a produtiva relação línguatexto, com temas variados (cf. NEVES, 2006; PAULIUKONIS, 2011), incluindo os do plano de unidades menores como o da sentença/período, não foi atestada.

Ademais, ao deixar a cargo do professor ou do livro didático discutir ou não os conceitos implícitos nas questões de base puramente semântica, o material acaba por contribuir, ainda, para a instabilidade do currículo de Língua Portuguesa nas escolas.

Essa diagnose teve por objetivo não apontar as falhas do material analisado, mas informar as práticas pedagógicas vigentes. Isso se justifica, pois, para se proporem estratégias didáticas produtivas para o trabalho com o componente linguístico, é preciso ter conhecimento das orientações curriculares e da abordagem que se têm praticado.

Entende-se ser necessário e urgente o desenvolvimento de atividades que focalizem o componente linguístico sem perder de vista, em uma abordagem reflexiva, sua sistematicidade e sua variabilidade, e integrando-o à produção de sentidos no plano textual, sempre que possível. Em outras palavras, os três eixos podem ser conjugados no ensino de gramática, conforme propõe Vieira $(2014,2018)$.

\section{REFERÊNCIAS}

BORTONI-RICARDO, S. M. Nós cheguemu na escola, e agora? Sociolinguística e Educação. São Paulo: Parábola Editorial, 2005. 
BRASIL. Secretaria de Educação Fundamental. Parâmetros curriculares nacionais: terceiro e quarto ciclos do ensino fundamental: língua portuguesa. Brasília: MEC/SEF, 1998.

DURVAL, L. F. S. Uma experiência didática com o futuro do presente: reflexão linguística, variação e ensino. In. VIEIRA, S. R. (org.). Gramática, variação e ensino: diagnose e propostas pedagógicas. São Paulo: Blucher, 2018. p. 155-172.

FARACO, C. A. Norma culta brasileira - desatando alguns nós. São Paulo: Parábola Editorial, 2008

FRANCHI, C. Mas o que é mesmo "gramática"? São Paulo: Parábola Editorial, 2006.

LABOV, W. Padrões Sociolinguísticos. Tradução Marcos Bagno, Marta Scherre e Caroline Cardoso. São Paulo: Parábola, 2008.

LIMA, M. D. A. O. O quadro pronominal: atividades lúdicas para o ensino de gramática e variação. In: VIEIRA, S. R. (org.). Gramática, variação e ensino: diagnose e propostas pedagógicas. Rio de Janeiro: Letras UFRJ, 2017.

MARCUSCHI, L. A. Produção textual, análise de gêneros e compreensão. São Paulo: Parábola Editorial, 2008.

NEVES, M. H. M. Texto e gramática. São Paulo: Contexto, 2006.

NEVES, M. H. M. A gramática passada a limpo: conceitos, análises e parâmetros. São Paulo: Parábola Editorial, 2012.

PAULIUKONIS, M. A. L. Texto e contexto. In: VIEIRA, S. R.; BRANDÃO, S. F. (org.). Ensino de gramática: descrição e uso. 2. ed. São Paulo: Contexto, 2011. p. 237-258.

PIRES DE OLIVEIRA, R. de; QUAREZEMIN, S. Gramáticas na escola. Petrópolis: Vozes, 2016.

RIO DE JANEIRO. Secretaria Municipal de Educação. Orientações Curriculares: Áreas Específicas. Rio de Janeiro, 2013.

RIO DE JANEIRO. Secretaria Municipal de Educação. Produção textual: critérios de avaliação. Rio de Janeiro, 2016. Disponível em: http://www.rioeduca.net/recursosPedagogicos.php. Acesso em: 13 mar. 2018. 
RIO DE JANEIRO. Secretaria Municipal de Educação. Cadernos Pedagógicos, 2016. Disponível em: http://www.rioeduca.net/recursosPedagogicos.php. Acesso em: 13 mar. 2018.

VIEIRA, S. R. Orientações oficiais para o ensino de gramática: uma proposta em três frentes de trabalho. Trabalho apresentado no V Encontro Nacional das Licenciaturas (ENALIC), UFRN, Natal, 2014.

VIEIRA, S. R. Três eixos para o ensino de gramática: uma proposta experimental. In: NORONHA, C. A.; SÁ JR., L. A. de. (org.). Escola, ensino e linguagem [recurso eletrônico]. Natal: EDUFRN, 2017. p. 78-104. Disponível em: http://repositorio.ufrn.br. Acesso em: 13 mar. 2018.

VIEIRA, S. R. (org.). Gramática, variação e ensino: diagnose e propostas pedagógicas. São Paulo: Blucher, 2018.

WEINREICH, U.; LABOV, W.; HERZOG, M. Fundamentos empíricos para uma teoria da mudança linguística. Tradução Marcos Bagno. Revisão técnica: Carlos Alberto Faraco. São Paulo: Parábola Editorial, 2006 [1968].

ZILLES, A. M. S.; FARACO, C. A. (org.). Pedagogia da variação linguística: língua e diversidade. São Paulo: Parábola Editorial, 2015. p. 19-30. 